\title{
Immunosuppressive Medication Adherence in Kidney Transplant Patients
}

\author{
Jelena Lalića Radmila Veličković-Radovanovića-c Branka Mitićc \\ Goran Paunovićc Tatjana Cvetkovićc \\ ${ }^{a}$ Department of Pharmacy, Faculty of Medicine, University of Niš, and ${ }^{b}$ Department of Pharmacotherapy, and \\ ${ }^{\circ}$ Clinic of Nephrology, Clinical Centre Niš, Niš, Serbia
}

\section{Key Words}

Adherence · Immunosuppressants · Kidney transplantation ·

Tacrolimus

\begin{abstract}
Objectives: To assess the degree of immunosuppressive medication adherence in kidney transplant patients (KTPs) and to determine if there is a difference in the rate of adherence to tacrolimus ( $\mathrm{Tac})$, cyclosporine ( $\mathrm{Cs} A)$ and sirolimus (Sir). Subjects and Methods: From a total of 63 KTPs treated at the Clinic of Nephrology, Clinical Centre Niš, Serbia, 60 participated in the study by responding to questionnaires. They were divided into the adherence group $(n=43)$ and the nonadherence group $(n=17)$ according to their degree of adherence which was measured using a validated survey form, the simplified medication adherence questionnaire. The KTP adherence to the different immunosuppressive regimens (Tac, CsA and Sir) was compared. Statistical analysis was performed using the Student t test. Results: Adherence was observed in $43(71.7 \%)$ patients, and only 17 (28.3\%) did not follow the prescribed therapy. The estimated glomerular filtration rate was significantly lower in the nonadherence group $(38.52 \pm 18.22 \mathrm{ml} / \mathrm{min})$ than in the adherence group
\end{abstract}

$(52.43 \pm 16.91 \mathrm{ml} / \mathrm{min}, \mathrm{p}<0.05)$. With regard to the Tac level, a significant difference was also found between the adherers and the nonadherers $(6.30 \pm 2.06$ vs. $5.0 \pm 1.52 \mathrm{ng} / \mathrm{ml}, \mathrm{p}<$ 0.05). Conclusion: The KTPs in this study demonstrated a high level of adherence. Nonadherence was associated with worse graft function and a lower Tac level. Knowledge about the degree of adherence could help the early identification of nonadherent patients and the development of strategies to improve this.

(c) 2014 S. Karger AG, Basel

\section{Introduction}

Kidney transplantation is the optimal treatment for end-stage renal disease. The life expectancy of transplant patients is significantly improved compared to that of agematched wait-listed patients on dialysis. Although kidney transplantation prolongs life and improves the quality of life, it remains a chronic illness, in which patients require continued medical follow-up for the monitoring of graft function and medication for the rest of their lives $[1,2]$. The survival of the transplanted kidney is dependent on the prescribed immunosuppressive medications [3].

\section{KARGER}

E-Mail karger@karger.com www.karger.com/mpp
(C) 2014 S. Karger AG, Basel 1011-7571/14/0234-0351\$39.50/0

Karge

Open access

This is an Open Access article licensed under the terms of the Creative Commons Attribution-NonCommercial 3.0 Unported license (CC BY-NC) (www.karger.com/OA-license), applicable to the online version of the article only. Distribution permitted for non-commercial purposes only.
Radmila Veličković-Radovanović

Department of Pharmacy, Faculty of Medicine, University of Niš Bulevar dr Zorana Djindjića 81

YU-18000 Niš (Serbia)

E-Mailfarmakoterapija@yahoo.com 
It is well known that nonadherence to immunosuppressive therapy after organ transplantation is strongly associated with negative medical outcomes [4]. Kidney graft recipients who do not adhere to their prescribed medication regimens are at an increased risk of infection, episodes of acute and chronic rejection and, ultimately, graft loss [4]. It has been reported that such nonadherence accounts for $16.3-36.4 \%$ of graft losses and $19.9 \%$ of late acute rejections [5]. Poor adherence by kidney transplant patients (KTPs) is not only a significant obstacle to allograft maintenance, but may also result in the need for dialysis, decreased productivity and a reduced quality of life for the patient [6].

A key problem is the difficulty of discovering nonadherence behavior. Medication adherence can be measured using a variety of methods, but none has emerged as the gold standard [7]. Indirect methods such as patient questionnaires and diaries, self-reports, interviews with patients and rates of prescription refills [8] are the simplest and most common methods [9]. The pill-count method and electronic medication monitors like the MEMS (Medication Event Monitoring System) are also reliable for assessing medication adherence [10]. Direct methods for the evaluation of therapeutic adherence like measuring concentrations of drugs or metabolites or the biological markers in the patients' biological fluids can also be applied [11]. However, questionnaires and selfreport methods are generally the most cost-effective and time-efficient way of obtaining an indication of adherence; the biological methods are more objective but also more expensive and not necessarily more accurate.

Evaluation of medication adherence is an important preliminary step toward developing interventions and guidelines for improving poor adherence to immunosuppressive medication among KTPs. Research on this problem is still insufficient in our country, and there are no data on degrees of KTP adherence or the consequences of nonadherence. The purpose of this study was to assess the degree of medication adherence among KTPs by using a validated survey form and also to determine if there is a difference in the rate of adherence to tacrolimus (Tac), cyclosporine (CsA) and sirolimus (Sir).

\section{Subjects and Methods}

\section{Study Population}

This cross-sectional study was carried out at the Clinic of Nephrology, Clinical Centre Niš, Serbia. All 63 KTPs attending follow-up visits from January to April 2013 were approached for inclusion in the study. Inclusion criteria were: (1) age of at least
18 years; (2) kidney transplantation at least 1 year previously; (3) immunosuppressant therapy (Tac, CsA or Sir) for 1 consecutive year, and (4) being the recipient of only one renal transplant at the time of study enrollment. The causes of end-stage kidney disease were: chronic glomerulonephritis $(n=37)$, chronic pyelonephritis $(n=16)$ and diabetic nephropathy $(n=7)$. All patients were on immunosuppressive therapy. In addition to immunosuppressants, they were taking mycophenolate mofetil and prednisone.

The study was approved by the Ethics Committee of the Faculty of Medicine, University of Niš. Informed consent was obtained from all participants, participation in the study was voluntary and the obtained information was treated confidentially.

Data Collection and Assessment of Medication Adherence

The patients were interviewed personally by a pharmacist (J.L.) with structured questionnaires regarding sociodemographic profile and adherence to immunosuppressive therapy. The simplified medication adherence questionnaire (SMAQ) was used to measure adherence as previously described [12]. This questionnaire was developed as a modification of the Morisky-Green questionnaire for measuring adherence to antiretroviral treatment in patients with AIDS. A Spanish version adapted for use in KTPs was translated into Serbian for this study. It consisted of six questions evaluating different aspects of patient adherence, i.e. forgetfulness, routine, adverse effects and the quantification of omissions. Adherence to therapy was assessed according to the answers to the following questions:

- Do you always take your medication at the appropriate time?

- When you feel worse, have you ever discontinued taking your medication?

- Have you ever forgotten to take your medication?

- Have you ever forgotten to take your medication on the weekend?

- In the last week, how many times did you fail to take your prescribed dose?

- Since your last visit, how many whole days have gone by in which you did not take your medication?

All questions were read out to the participant, and the answers were recorded. Patients were classified according to their responses to the questionnaire. The first four questions were answered positively or negatively using the Yes/No format. The response format for the fifth item was on a 5-point scale with the following options: never, 1-2 times, 3-5 times, 6-10 times and $>10$ times. The last item required participants to indicate the number of days. Based on their responses to the SMAQ items, patients were classified as being either adherent or nonadherent. The adherence group consisted of patients who showed a satisfactory level of adherence. Patients were considered adherent if they replied to all questions with an adherence answer in all six SMAQ items, i.e. 'Yes' in the first, 'No' in the next three items and not having missed more than 2 doses during the last week or having failed to take the medication on not more than 2 days during the last 3 months. The nonadherence group represented patients who had a low level of adherence. A patient was considered nonadherent if he/she responded to any of the six items on the scale with a nonadherence answer, i.e. 'No' in the first, 'Yes' in the following three items, and in terms of quantification, if the patient has missed more than 2 doses during the last week or had failed to take medication on more than 2 days during the last 3 months. 
Other details including donor type (living/deceased), immunosuppressants (type, dose and concentration), complexity of medication regimen, i.e. the number of medications/pills), time since the transplant, primary kidney disease, weight and blood pressure were retrieved from the medical files. The estimated glomerular filtration rate (eGFR) was calculated by the MDRD (Modification of Diet in Renal Disease) formula. The concentrations of immunosuppressants in adherent and nonadherent patients were compared by means of therapeutic monitoring. Blood samples were drawn on the same day as completion of the questionnaire.

\section{Statistical Analysis}

The Statistical Package for the Social Sciences (SPSS version 19.0) software was used to analyze the data obtained from the questionnaires. The Student $t$ test was used to evaluate between-group differences in age, gender, time since the transplant, level of immunosuppressant, number of drugs, eGFR, blood pressure value and donor type. A p value $<0.05$ was considered statistically significant. The results are presented as mean value \pm standard deviation.

\section{Results}

Of the 63 patients approached for this study, 1 was ineligible and 2 declined to participate, thereby giving a total of 60 who consented, i.e. a response rate of $96.8 \%$. The mean age of the 60 kidney transplant recipients was 44.45 \pm 11.37 years (range $21-69$ ). Forty-six (76.7\%) patients received grafts from living donors, and the mean time since transplantation was $5.34 \pm 3.84$ years (range 1-17). The mean weight of the patients was $75.69 \pm 13.92 \mathrm{~kg}$. There were 38 (63.3\%) male patients and 22 (36.7\%) females. Tac was prescribed as an initial posttransplant immunosuppressive therapy in $45(75 \%)$ of the cases, while $11(18.3 \%)$ received CsA and 4 (6.7\%) received Sir. The mean daily dose of Tac prescribed upon inclusion in the study was $3.13 \pm 2.34 \mathrm{mg}$ (range 1-16), and the mean level was $5.96 \pm 2.0 \mathrm{ng} / \mathrm{ml}$ (range 3.1-12.7). The mean daily dose of CsA and Sir was $167.73 \pm 44.46$ (range 100220 ) and $1.83 \pm 0.29 \mathrm{mg}$ (range 1.5-2), respectively. The mean level of CsA was $96.14 \pm 22.91 \mathrm{ng} / \mathrm{ml}$ (range 43.2126.8 ) and that of Sir was $7.22 \pm 0.62 \mathrm{ng} / \mathrm{ml}$ (range 6.777.93). Serum levels of immunosuppressants were within clinical targets. The results of the evaluated clinical and demographic data of the selected patients are summarized in table 1.

According to the SMAQ, the rate of adherence was $71.7 \%$. The observed nonadherence rates were higher in the patients who received CsA $(36.4 \% ; n=4)$ than in those who received $\operatorname{Tac}(26.7 \% ; \mathrm{n}=12)$ and $\operatorname{Sir}(25 \% ; \mathrm{n}=1)$, but there were no statistically significant differences.

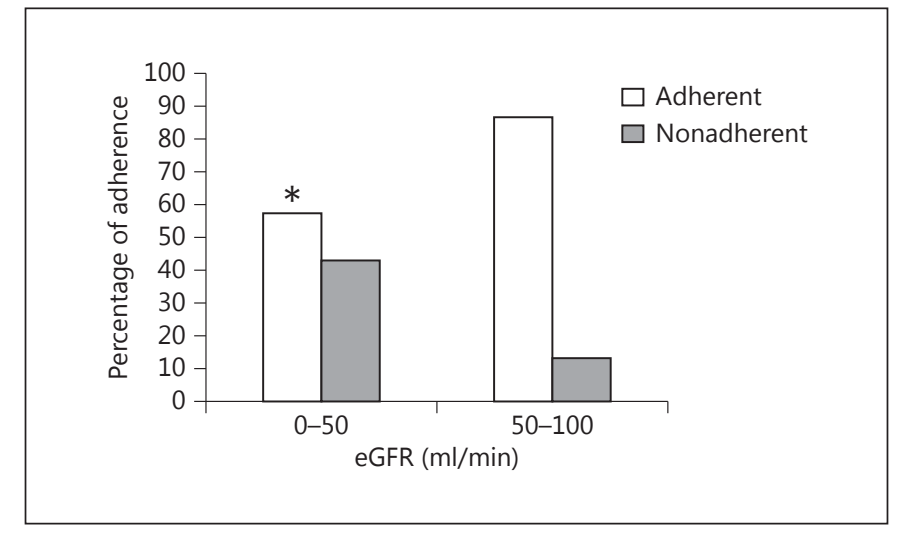

Fig. 1. eGFR in KTPs. ${ }^{*} \mathrm{p}<0.05$.

Table 1. Clinical and demographic characteristics according to medication adherence

\begin{tabular}{lccc}
\hline & Nonadherent & Adherent & $\begin{array}{l}\mathrm{p} \\
\text { value }\end{array}$ \\
& & & \\
& & & \\
Gender & & & \\
$\quad$ Male & $9(41.0)$ & $30(79.0)$ & 0.14 \\
$\quad$ Female & $13(59.1)$ & \\
Age, years & $46.35 \pm 12.72$ & $43.63 \pm 10.66$ & 0.44 \\
Time since transplant, & & & \\
$\quad$ years & $6.49 \pm 4.35$ & $7.45 \pm 4.40$ & 0.19 \\
Donor type & & & \\
$\quad$ Live & $11(23.9)$ & $35(76.1)$ & 0.19 \\
$\quad$ Deceased & $6(42.9)$ & $8(57.1)$ & \\
Immunosuppressant & & & \\
$\quad$ Tac & $12(26.7)$ & $33(73.4)$ & \\
$\quad$ CsA & $4(36.4)$ & $7(63.7)$ & \\
$\quad$ Sir & $1(25.0)$ & $3(75.0)$ & \\
Tac levela, ng/ml & $5.0 \pm 1.52$ & $6.30 \pm 2.06$ & 0.03 \\
CsA level, ng/ml & $104.68 \pm 20.04$ & $99.27 \pm 13.03$ & 0.65 \\
Sir level, ng/ml & 7.93 & $6.87 \pm 0.14$ & \\
Drugs, $\mathrm{n}$ & $7.65 \pm 2.69$ & $6.83 \pm 1.71$ & 0.26 \\
eGFR, ml/min & $38.52 \pm 18.22$ & $52.43 \pm 16.91$ & 0.01 \\
Blood pressure, mm Hg & $131.47 / 82.47$ & $123.57 / 77.62$ & 0.10 \\
\hline
\end{tabular}

Figures denote $\mathrm{n}(\%)$ unless otherwise indicated.

${ }^{\mathrm{a}} \mathrm{p}<0.05$.

Age and gender did not differ significantly between the adherence and nonadherence groups. There were also no significant differences between adherent and nonadherent patients in time since the transplant, donor type, number of drugs prescribed and blood pressure value. Graft function, evaluated by MDRD eGFR was worse in 
Table 2. Leading reasons for the nonadherence in KTPs

\begin{tabular}{|c|c|c|c|}
\hline \multirow[t]{2}{*}{$\begin{array}{l}\text { Reasons for } \\
\text { nonadherence }\end{array}$} & \multicolumn{3}{|c|}{$\begin{array}{l}\text { Patients on immunosuppressive } \\
\text { therapy, } \mathrm{n}(\%)\end{array}$} \\
\hline & $\mathrm{Tac}$ & CsA & Sir \\
\hline Forgetfulness & $11(91.7 \%)$ & $3(75 \%)$ & $1(100 \%)$ \\
\hline Intentional nonadherence & $1(8.3 \%)$ & $1(25 \%)$ & 0 \\
\hline
\end{tabular}

the nonadherent patients $(38.52 \pm 18.22 \mathrm{ml} / \mathrm{min})$ than in the adherent patients $(52.43 \pm 16.91 \mathrm{ml} / \mathrm{min}, \mathrm{p}<0.05$; fig. 1).

Regarding the level of immunosuppressants, a significant difference was found between the adherers (6.30 \pm $2.06 \mathrm{ng} / \mathrm{ml})$ and nonadherers $(5.0 \pm 1.52 \mathrm{ng} / \mathrm{ml})$ who received Tac $(\mathrm{p}<0.05)$. Tac levels for nonadherent patients were significantly lower but were still within clinical targets.

The leading reasons for nonadherence in KTPs are listed in table 2. The most important factor for poor adherence was forgetfulness in $15(88.2 \%)$ patients. Intentional nonadherence (e.g. the patient deciding to discontinue taking medication because he/she felt worse) was a factor in $2 / 17(11.8 \%)$ nonadherent patients.

\section{Discussion}

Based on all six items in the SMAQ, adherence to therapy was high (71.7\%) in our KTP population. Our findings show a statistically significant association between adherence and Tac levels and between adherence and eGFR. No statistically significant relationships were found between adherence and time since the transplant, donor type, blood pressure value or number of drugs (table 1).

The effects of age and gender on the rate of adherence to medication were also nonsignificant. The effect of gender in this study differs from that in Lertmaharit et al. [13], where female patients had better adherence, and Hertz et al. [14], where male patients were more likely to adhere to therapy. However, our results are consistent with those of Senior et al. [15], who could not find a relationship between gender and adherence to medication. With regard to age, the degree of adherence decreased as the age of the patients increased. This was probably due to memory loss in elderly patients caused by dementia or Alzheimer's disease, impaired vision and hearing that might increase the potential for mistakes in taking medications and comorbidities that required taking several drugs at the same time. These general characteristics are common among elderly patients in most societies as reported previously [16].

Another important finding of this study was that graft function evaluated by MDRD eGFR was worse in nonadherent patients. This confirmed the results of a previous Brazilian study [17] in which a high prevalence of nonadherence to immunosuppressive drugs was associated with a lower eGFR. The other factor relating to nonadherence in our study was the lower Tac level, also confirming results of previous studies $[18,19]$ in which nonadherent patients had drug concentrations that were below the clinical target.

Although data in a previous study suggest that the KTPs are more adherent to Tac than to CsA [18], we found no significant difference in the level of adherence to Tac when compared to CsA and Sir. The nonsignificant, highest level of nonadherence, i.e. 4 (36.4\%), was reported in the patients receiving CsA. We found that nonadherence of the whole study group of patients (according to the SMAQ item) was more common due to forgetfulness than to intentional nonadherence. These findings confirmed those of a British research study which reported that intentional nonadherence was low (13.8\%) compared to unintentional nonadherence to immunosuppressive medication (62.4\%) [20].

Of the total of $60 \mathrm{KTPs}$ clinically examined with the SMAQ, we identified only $28.3 \%$ as nonadherent. The strict definition of adherence (a classification based on all six items) that we used makes our finding of a rate of $>70 \%$ adherence even more worthy of note. It has been reported that, in general, KTPs adhere to treatment. Indeed, we found only a small number to be nonadherent. Other studies employing different diagnostic criteria for nonadherence with immunosuppressive treatment have found prevalence rates of between 23 and 35\% in KTPs $[5,19,21,22]$. This could be due to the poor health-related quality of life experienced during dialysis treatment. A probable explanation for good adherence could be due to the fear of losing the graft and being forced to go back on dialysis. Graft loss has been associated with significant worsening of the health-related quality of life of patients and a negative impact on the social, financial and psychological aspects of their lives [23, 24].

In previous research conducted in Spain using the SMAQ, the adherence rates of KTPs on Tac were significantly lower (39.0 and $41.8 \%$ ) than the rate in our study (71.7\%) [12]. The adherence criteria of our study were 
consistent with those of the Spanish study. According to the other measuring instruments (i.e. the BASIS scoring system and the control of the dispensing of medication), the adherence rate findings of Brahm et al. [17] and Lennerling and Forsberg [25], i.e. 41.3 and 46\%, respectively, were also lower than our rate of $71.7 \%$. A possible reason for poor adherence could be the many unpleasant side effects of immunosuppressive agents, including feeling worse and an increased risk of nephrotoxicity and weight gain. For an improvement in adherence to medication, we recommend counseling sessions by healthcare professionals, continuing patient education about the disease and upgrading patients' socioeconomic levels. Strategies should be developed that can support patients in establishing medication routines and foreseeing/dealing with likely disruptions, along with technology-assisted devices and the simplification of drug regimens and reductions in drug dosage. We also recommend the use of pillboxes, keeping a diary and being reminded to take medicine by setting an alarm or planning it to coincide with regular activities like brushing teeth or eating meals $[26,27]$.

\section{Study Limitations}

The limitations of this study were its cross-sectional design and the small study population.

\section{Conclusion}

Our study population of patients with transplanted kidneys showed satisfactory adherence to medication. An important finding was that nonadherence was associated with inefficient graft function and a lower Tac level. Hence, taking immunosuppressive medications according to the prescribed plan is crucial for the survival of the transplanted kidney.

\section{Acknowledgement}

This study was supported by a grant from the Ministry of Education and Science of the Republic of Serbia - Project No. 41018.

\section{References}

1 Theofilou P: Identifying risk factors associated with compliance to medication in elderly kidney transplant patients. J Transplant Technol Res 2012;2:2-3.

2 McKay DB, Steinberg SM: Kidney Transplantation: A Guide to the Care of Kidney Transplant Recipients. New York, Springer, 2010, pp 371-372.

3 De Geest S, Abraham I, Dunbar-Jacob J, et al: Behavioral strategies for long-term survival of transplant recipients; in Metry J, Meyer U (eds): Drug Regimen Compliance: Issues in Clinical Trials and Patient Management. Chichester, John Wiley \& Sons, 1999, pp 163 180.

4 Constantiner M, Cukor D: Barriers to immunosuppressive medication adherence in highrisk adult renal transplant recipients. Dial Transplant 2011;40:60-66.

5 Schmid-Mohler G, Pechula Thut M, Wüthrich RP, et al: Non-adherence to immunosuppressive medication in renal transplant recipients within the scope of the integrative model of behavioral prediction: a cross-sectional study. Clin Transplant 2010;24:213-222.

6 Gaston R, Hudson S, War M, et al: Late renal allograft loss: noncompliance masquerading as chronic rejection. Transplant Proc 1999;31: 21S-23S.
7 Papajcik D, Mastroianni B, Goormastic M, et al: A tool to identify risk factors for noncompliance in the adult renal transplant recipient. Transplant Proc 1999;31:84-86.

$\checkmark 8$ Osterberg L, Blaschke T: Adherence to medication. N Engl J Med 2005;353:48-497.

-9 Girerd X, Hanon O, Anagnostopoulos K, et al: Assessment of antihypertensive compliance using a self-administered questionnaire: development and use in a hypertension clinic (in French). Presse Med 2001;30:1044-1048.

10 Rudd P, Byyny RL, Zachary V, et al: Pill count measures of compliance in a drug trial: variability and suitability. Am J Hypertens 1998; 1:309-312.

11 Liu H, Kaplan AH, Wenger NS: Measuring patient adherence. Ann Intern Med 2002;137: 72-73.

12 Ortega Suárez FJ, Sánchez Plumed J, Pérez Valentín MA, et al: Validation on the simplified medication adherence questionnaire (SMAQ) in renal transplant patients on tacrolimus. Nefrologia 2011;31:690-696.

13 Lertmaharit S, Kamol-Ratankul P, Sawert H: Factors associated with compliance among tuberculosis patients in Thailand. J Med Assoc Thai $2005 ; 88: 149-156$.
14 Hertz RP, Unger AN, Lustik MB: Adherence with pharmacotherapy for type 2 diabetes: a retrospective cohort study of adults with employer-sponsored health insurance. Clin Ther 2005;27:1064-1073.

15 Senior V, Marteau TM, Weinman J: Self-reported adherence to cholesterol-lowering medication in patients with familial hypercholesterolaemia: the role of illness perceptions. Cardiovasc Drugs Ther 2004;18:475481.

16 Sweileh W, Aker O, Hamooz S: Effect of 'polypharmacy' and 'frequency' of drug dosing on rate of compliance among diabetic and hypertensive patients: a survey study in Palestine. An-Najah Univ J Res 2003;17:155-165.

17 Brahm MMT, Manfro RC, Mello D, et al: Evaluation of adherence to immunosuppressive drugs in kidney transplantation by control of medication dispensing. Transplant Proc 2012;44:2391-2393.

18 Chisholm MA, Mulloy LL, DiPiro JT: Comparing renal transplant patients' adherence to free cyclosporine and free tacrolimus immunosuppressant therapy. Clin Transplant 2005; 19:77-82.

19 Chisholm MA, Lance CE, Mulloy LL: Patient factors associated with adherence to immunosuppressant therapy in renal transplant recipients. Am J Health Syst Pharm 2005;62: 1775-1781. 
20 Griva K, Davenport A, Harrison M, et al: Non-adherence to immunosuppressive medications in kidney transplantation: intent vs. forgetfulness and clinical markers of medication intake. Ann Behav Med 2012;44:85-93.

21 Denhaerynck K, Dobbels F, Cleemput I, et al: Prevalence, consequences, and determinants of nonadherence in adult renal transplant patients: a literature review. Transpl Int 2005; 18 : 1121-1233.

22 Dew MA, DiMartini AF, De Vito DA, et al: Rates and risk factors for nonadherence to the medical regimen after adult solid organ transplantation. Transplantation 2007; 83:858873.
23 Maglakelidze N, Pantsulaia T, Tchokhonelidze I, et al: Assessment of health-related quality of life in renal transplant recipients and dialysis patients. Transplant Proc 2011;43: 376-379.

24 Theofilou P: Quality of life in patients undergoing hemodialysis or peritoneal dialysis treatment. J Clin Med Res 2011;3:132-138.
5 Lennerling A, Forsberg A: Self-reported nonadherence and beliefs about medication in a Swedish kidney transplant population. Open Nurs J 2012;6:41-46.

26 Aly NY, Omar AA, Badawy DA, et al: Audit of physicians' adherence to the antibiotic policy guidelines in Kuwait. Med Princ Pract 2012;21:310-317.

27 Katoue MG, Al Haqan A: Implementation and evaluation of a workshop on patient counseling about antidiabetic medications for final-year pharmacy students. Med Princ Pract 2013;22:489-494. 